\title{
The Influence of Geometry on the Fluid Dynamics of Continuous Settler
}

\author{
Flávia Daylane Tavares de Luna1,2, Andhros Guimarães da Silva², \\ Ardson dos Santos Vianna Júnior ${ }^{2}$ \\ ${ }^{1}$ Federal Institute of São Paulo-IFSP, Cubatão, Brazil \\ ${ }^{2}$ Department of Chemical Engineering, Polytechnic School, University of São Paulo, São Paulo, Brazil \\ Email: flavia.daylane@ifsp.edu.br, andhros@usp.br, ardson@usp.br
}

How to cite this paper: de Luna, F.D.T., da Silva, A.G. and dos Santos Vianna Júnior, A. (2020) The Influence of Geometry on the Fluid Dynamics of Continuous Settler. Open Journal of Fluid Dynamics, 10, 164-183. https://doi.org/10.4236/ojfd.2020.103011

Received: June 8, 2020

Accepted: July 7, 2020

Published: July 10, 2020

Copyright $\odot 2020$ by author(s) and Scientific Research Publishing Inc. This work is licensed under the Creative Commons Attribution International License (CC BY 4.0).

http://creativecommons.org/licenses/by/4.0/

(c) (i) Open Access

\begin{abstract}
Settlers are broadly used by industries for separating components with different densities, because they show operational facilities and high efficiency. As they use the action of gravity, they can treat great quantities of effluents with lower energy expenditure. However, the performance of the settler depends on the streamlines inside the equipment, which, in turn, are influenced by the characteristics of the suspended solids, the geometry, and dimensions of the tank. In this paper, the effect of the settler geometry properties on the hydrodynamic in a vertical circular cylindrical tank was investigated. The evaluated parameters were the feed pipe design, the dimensions of the piece of equipment, and the structure of settler bottom. The numerical simulations were performed using the package ANSYS-CFX 16.0. It was considered a turbulent, isothermal, and stationary flow. The Euler-Euler multiphase model and BSL-RSM model turbulence were applied. The recirculation zones were influenced by the separation tank geometrical form. The modification of the feed pipe in the original project reduced the mixture inside the feedwell. The increase of the sedimentation tank diameter improved the performance of water and solid separation, elevating the efficiency by $10.48 \%$, whilst the increase of the tank depth reduced the separation efficiency by $16.72 \%$, in comparison to the original project.
\end{abstract}

\section{Keywords}

Settler Design, Multiphase Flow, Sedimentation Efficiency, Circulation

\section{Introduction}

Sedimentation promotes the separation of particles suspended in the fluid by the action of gravity as well as the difference in density of involved components. This 
unit operation is an integral part of any water and sewer treatment station. Sedimentation tanks are some of the main equipment in a treatment station, especially in the purification of turbid flows [1] [2] [3] [4]. Therefore, it is crucial for a settler to works at its full potential.

However, the characteristics of the suspended solids are not the only factors that influence the separation performance of tanks. Fluid dynamics has a prominent role: the uniform flow field is essential to increase the efficiency of the sedimentation tank, allowing particles to settle within a shorter time [1] [5]. The existence of circulation regions decreases the tank effective volume and induces a high intensity of turbulence. According to Farrow et al. [6], White et al. [7], Goula et al. [1], and Shahrokhi et al. [8], the flow field inside the equipment depends on the characteristics of the suspended solids, the established boundary conditions, the geometry and the dimensions of the separator tank.

Computational fluid dynamics (CFD) has been largely employed in the study of fluids behavior in settlers, replacing part of some slow and expensive experiments. CFD can be used to increase the basic understanding of the internal processes and their interactions inside the tank, which can optimize projects and propose adaptations to reduce fluid recirculation zones and, consequently, increase the separation efficiency. However, to ensure that the results are consistent, the CFD model must be validated with experimental data or theoretical results [9] [10] [11].

Several authors have been studying sedimentation tanks by using CFD, in order to predict flow patterns. Al-Sammarraee et al. [12] studied sedimentation in a horizontal tank, using the LES turbulence approach. The flow presented recirculation near to the inlet and the outlet region of the settler, which probably inhibited the sedimentation of smaller diameter particles that tended to be evenly distributed in the equipment. The separation efficiency obtained was about $18 \%$ for $20 \mu \mathrm{m}$ diameter particles. Tarpagkou and Pantokratoras [13] used the Euler-Lagrange multiphase model and the RNG $\kappa$ - $\varepsilon$ turbulence model. They studied fluid dynamics in a lamellar settler and compared it with the flow behavior obtained by a conventional settler. The great fluid recirculations observed in the conventional tank were divided into smaller vortices in the lamellar settler, consequently, the phase separation efficiency obtained using the common equipment was about $75 \%$, which increased to $93 \%$ in the lamellar tank.

Furthermore, different numerical studies aim to find new and useful methods to increase separation efficiency. White et al. [7] studied the influence of baffles on fluid dynamics within the feedwell. The velocity fields were measured using the LDV technique and compared to the results obtained numerically. The authors concluded that the presence of baffles increased the permanence time and the mixing of the fluid in the feedwell, which may be desirable for an industrial process.

Goula et al. [1] studied geometric adaptation in a rectangular settler. The authors proposed stretching the inlet piping of the suspension to target the flow into the sedimentation region. For this, the FLUENT package was used, using the 
Lagrange multiphase model, considering one way coupling, and the SST turbulence model. With this modification, no recirculation zones near the heavier component outlet were observed, reducing the chance of resuspension of the particles already deposited.

Al-Sammarraee and Chan [2] studied the horizontal settler with vertical baffles. Separation efficiency for particles of $20 \mu \mathrm{m}$ diameter increased from $18 \%$, in the tank without baffle, to about $25 \%$ in the settler with four baffles. For the authors, the baffles acted as barriers and effectively repressed the horizontal flow velocities, forcing the particles to move towards the bottom of the tank.

Rostami et al. [3] presented the numerical study of different types of input structures in rectangular primary clarifier designs. The authors showed that having two or three inlet access of fluid caused smaller recirculation zones in the tank when compared to the case of single inlet access. For cases with more than one inlet access, the uniform flow was generated over shorter distances, and the turbulent kinetic energy was considerably lower.

Shahrokhi et al. [4] studied different positioning configurations of baffles in a rectangular sedimentation tank. They verified that the addition of baffles at appropriate places reduced the size of recirculation zones, the kinetic energy, and the maximum velocity.

Panda et al. [11], using laminar flow and the three-phase flow application Euler-Euler multiphase model, studied several settings for inlet positioning in a continuous gravitational settler, and they observed that the design provided a longer retention time of the mixture in the tank, which resulted in higher separation efficiency.

It is worth mentioning that, although the scrapers are essential in the transport of bed material to the underflow, they do not significantly influence the flow that occurs in the sedimentation region in wastewater treatment tanks [9] [14]. For this reason, several authors neglect the presence of scrapers in their studies of fluid dynamics in settlers [5] [7] [10] [12] [15] [16].

From this situation presented, the aim of this paper is to evaluate how the geometry of a vertical cylindrical settler tank affects the separation efficiency. The parameters evaluated were the feed pipe design, diameter and depth dimensions of the equipment and the inclination of the settler tank base. In order, we used the ANSYS-CFX 16.0 package to perform tridimensional simulations. The analysis of fluid dynamics was performed by flow lines, turbulent kinetic energy, the volumetric fraction of solids and separation efficiency.

\section{Fundamentals}

\subsection{Multiphase Model}

The multiphase flow within the settler may be modelled based on the Euler-Euler [11] [16] or the Euler-Lagrange approach. The Euler-Lagrange multiphase model with one or two coupling ways should not be applied to systems that present particles volumetric fractions exceeding 10\% - 12\% [17], despite being widely used 


\section{[12] [15] [18].}

As there are regions with high concentrations of solid phase in settlers, the Euler-Euler multiphase model is the appropriate one to be used. This model assumes that the momentum equations are solved for each phase and the coupling among them is given by interfacial transference [19].

The following assumptions were made 1) Newtonian and incompressible fluid with constant physicochemical properties; 2) isothermal, stationary and turbulent flow; 3) mass transfer and mass generation were not considered; 4) lift force, wall lubrication force, virtual mass force, and solid pressure force were neglected; 5) smooth and static wall; 6) model of particle interfacial transfer considered, and 7) dispersed phase with a constant diameter size of the particle.

With these considerations, the Reynolds-averaged Navier-Stokes (RANS) equations become:

$$
\begin{gathered}
\nabla \cdot\left(f_{\alpha} \rho_{\alpha} \bar{U}_{\alpha}\right)=0 \\
\nabla \cdot\left[f_{\alpha}\left(\rho_{\alpha} \bar{U}_{\alpha} \otimes \bar{U}_{\alpha}\right)\right] \\
=-f_{\alpha} \nabla p_{\alpha}+\nabla \cdot\left\{f_{\alpha}\left[\mu_{\alpha}\left(\nabla \bar{U}_{\alpha}+\left(\nabla \bar{U}_{\alpha}\right)^{\mathrm{T}}\right)-\rho_{\alpha} \overline{u_{i}^{\prime} u_{j}^{\prime}}\right]\right\}+\bar{S}_{M \alpha}+\bar{M}_{\alpha \beta}
\end{gathered}
$$

where the $\alpha$ subscript represents one phase of the suspension. $f, \rho$ and $\bar{U}$ are the volumetric fraction, specific mass and velocity, respectively; $p$ is the pressure; $\mu$ and $-\rho \overline{u_{i}^{\prime} u_{j}^{\prime}}$ represent dynamic viscosity and Reynolds stress tensor, respectively. $\bar{S}_{M \beta}$ represents the sum of the gravitational force per unit volume of the phase and a buoyancy force per unit volume of the phase (on the solid). On the liquid, $\bar{S}_{M \alpha}$ represents the sum of the gravitational force per unit volume and the opposite reaction of the buoyancy force per unit volume. $\bar{M}_{\alpha \beta}$ is the sum of the interfacial forces per unit volume of the phase, here defined by the sum of the drag force per unit volume of the phase $\left(\bar{M}_{\alpha \beta}^{D}\right)$ and turbulent dispersion force per unit volume of the phase $\left(\bar{M}_{\alpha \beta}^{T D}\right)$ (Equation (3)):

$$
\bar{M}_{\alpha \beta}=\bar{M}_{\alpha \beta}^{D}+\bar{M}_{\alpha \beta}^{T D}
$$

The drag force is given by the model proposed by Gidaspow [20]:

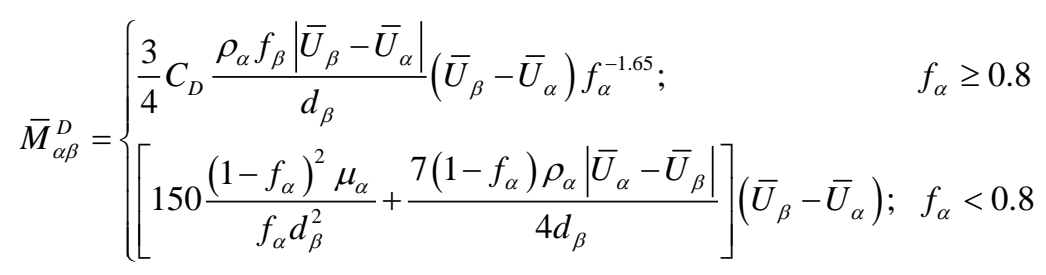

where $d_{\beta}$ is the particle diameter and $C_{D}$ is the drag coefficient, determined by Equation (5) [20]:

$$
C_{D}= \begin{cases}\frac{24}{f_{\alpha} \times \operatorname{Re}}\left[1+0.15\left(f_{\alpha} \times R e\right)^{0.687}\right] ; & f_{\alpha} \times R e<1000 \\ 0.44 ; & f_{\alpha} \times R e \geq 1000\end{cases}
$$

where $R e$ is the Reynolds number.

The turbulent dispersion force used here was proposed by Lopez de Bertoda- 
no et al. [21]:

$$
\bar{M}_{\alpha \beta}^{T D}=-C_{T D} \rho_{\alpha} \kappa_{\alpha} \nabla f_{\beta}
$$

where $\kappa$ represents the turbulent kinetic energy. $C_{T D}$ is the turbulent dispersion coefficient that considers the average of the turbulent tensions in all directions.

\subsection{Turbulence Model}

For this study, the BSL-RSM turbulence model was used, which is a model capable of accurately predicting the oscillations that were generated from the turbulent flow inside settler tanks [22]. It is based on the solution of a transport equation for each one of the six components of the Reynolds stress tensor (Equation (7)), with an additional expression for the turbulent dissipation rate [23] [24].

$$
\nabla \cdot\left[\rho \overline{u_{i}^{\prime} u_{j}^{\prime}} \otimes \bar{U}\right]=P+\Phi+\nabla \cdot\left[\left(\mu+\frac{\mu_{t}}{\sigma_{\kappa}}\right) \nabla \rho \overline{u_{i}^{\prime} u_{j}^{\prime}}\right]-\frac{2}{3} \delta \rho \omega \kappa \beta^{\prime}
$$

where $P$ is the term of rate production of Reynolds stresses; $\Phi$ is the correlation term of pressure-strain, determined by the LRR-QI model [25]. $\delta$ and $\omega$ represent the Kronecker delta function and the specific turbulent dissipation rate, respectively. The empirical constants have the following values: $\sigma_{k}=1.0$ and $\beta^{\prime}=1.3 . \mu_{t}$ is the turbulent viscosity given by:

$$
\mu_{t}=\rho \frac{\kappa}{\omega}
$$

The BSL-RSM model uses the modified turbulence frequency transport equation to determine the turbulent dissipation rate. The model consists of a combined function for the equation of turbulent dissipation, transforming it into a $\varepsilon$-equation for the external flow region and into a $\omega$-equation treatment closer to the wall.

\section{Materials and Method}

\subsection{Geometry and Mesh}

The design of the used prototype followed the geometry of the industrial circular clarifiers that can serve as thickeners [26], with a volume of $5.24 \times 10^{-3} \mathrm{~m}^{3}$, also studied by Luna et al. [22]. The original settler tank is composed by an inlet located on top of the equipment, and two outlets: one at the top (named here as clarified outlet) and the other at the center of the equipment base (named here as sludge outlet). Inside the settler, there is a central tube with a $0.080 \mathrm{~m}$ diameter, named feedwell. The suspension enters the feedwell through an axial pipe, non-concentric to the central axis, with diameter and length equal to $0.012 \mathrm{~m}$ and $0.075 \mathrm{~m}$, respectively, as described in Figure 1 .

The dimensions of the circular prototype were defined from the high-rate settlers, which present dimension ratios not so long; thus, the diameter-depth ratio may vary from 1:1 to 5:1 [27], as also used by Gheshlaghi et al. [28]. The length of the feedwell used in the studied prototype was about $85 \%$ of the length of the 


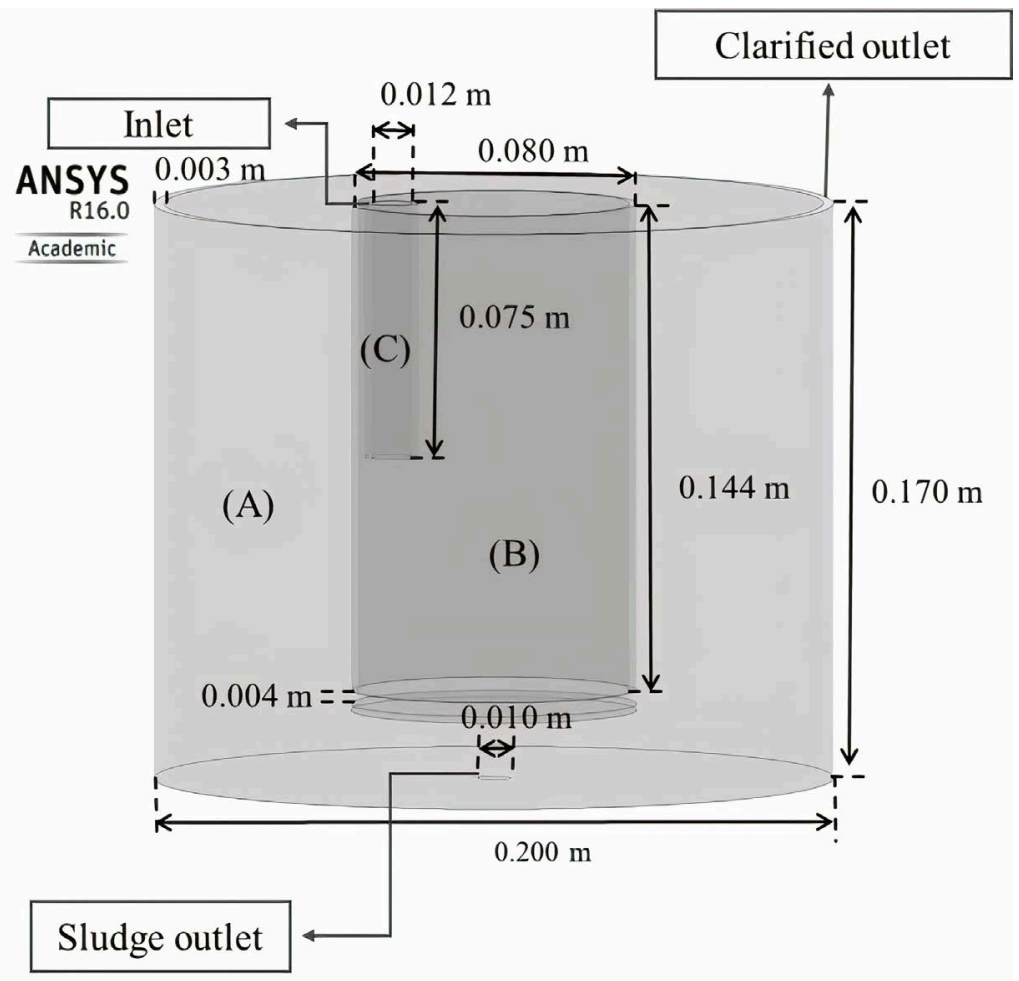

Figure 1. Original sedimentation tank created in ICEM CFD v.16.0; (A) sedimentation tank; (B) feedwell and (C) axial and no concentric feed pipe.

settler. However, according to Metcalf et al. [27], for an industrial piece of equipment, the conventional feedwell length is between $30 \%$ to $40 \%$ of the length of the tank. We applied an extensive length, aiming to prevent that short circuits in the feeding with high turbidity would interfere with the clarified overflowing performance on the settler top and, consequently, impaired the visualization of the solid/liquid interface in the experiments.

A structured mesh with hexahedral elements was generated using ICEM-CFD version 16.0. The blocking construction strategy was employed. Some meshes were created (sizes between 0.4 and 3.5 million volume elements) and some tests were performed to ensure the independence of results concerning the refinement used and to determine the best commitment among precision, numerical stability, convergence, and computational time. The mesh selected was composed of 2,450,410 cells (Figure 2). The difference between the predictions made for the mesh selected and the more refined ones was insignificant.

The modifications in the original geometry of the settler tank were proposed, and the fluid dynamics were analyzed through the streamlines, the solid volumetric fraction and the turbulent kinetic energy, factors related to the separation efficiency. As depicted in Table 1, the modifications performed were:

1) Suspension inlet structure (Figure 3): were considered the configuration of three tanks. The first (case 02) presents the feed pipe centralized inside the feedwell. The second (case 03) does not have a vertical pipe. In the third geometry, there is a tube extended through a vertical section, referred to as case 04 . 
Table 1. Cases studied.

\begin{tabular}{cccccc}
\hline Cases & Feed Pipe & $\begin{array}{c}\text { Settler Diameter } \\
(\mathrm{m})\end{array}$ & $\begin{array}{c}\text { Settler Depth } \\
(\mathrm{m})\end{array}$ & Settler Base & $\begin{array}{c}\text { Mesh size } \\
(\text { millions })\end{array}$ \\
\hline Case 01 & No change & 0.200 & 0.170 & No change & 2.45 \\
Case 02 & Centralized & 0.200 & 0.170 & No change & 2.45 \\
Case 03 & Without tube & 0.200 & 0.170 & No change & 2.16 \\
Case 04 & Increased 50\% & 0.200 & 0.170 & No change & 2.60 \\
Case 05 & No change & 0.200 & 0.204 & No change & 2.94 \\
Case 06 & No change & 0.200 & 0.238 & No change & 3.44 \\
Case 07 & No change & 0.240 & 0.170 & No change & 3.54 \\
Case 08 & No change & 0.280 & 0.170 & No change & 4.82 \\
Case 09 & No change & 0.200 & 0.170 & Conical-Inclination $1^{\circ}$ & 2.46 \\
Case 10 & No change & 0.200 & 0.170 & Conical-Inclination $5^{\circ}$ & 2.49 \\
Case 11 & No change & 0.200 & 0.170 & Conical-Inclination $8^{\circ}$ & 2.52 \\
\hline
\end{tabular}

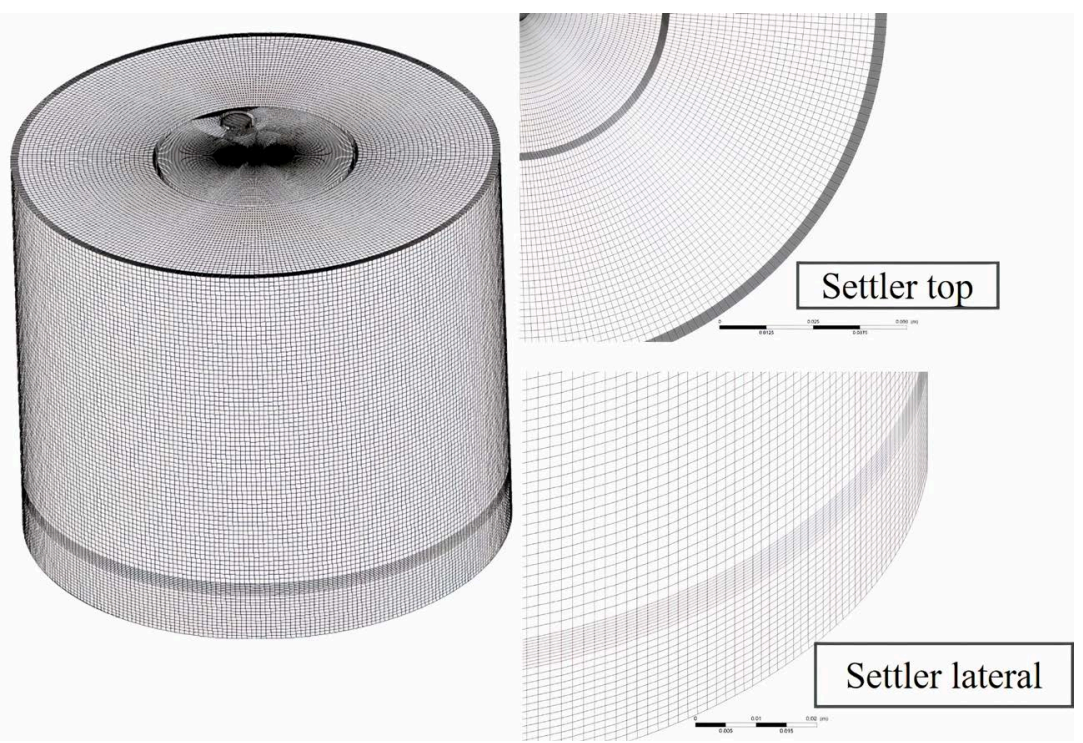

Figure 2. Representation of the hexahedral mesh used in the numerical study. Source: Luna et al. [22].
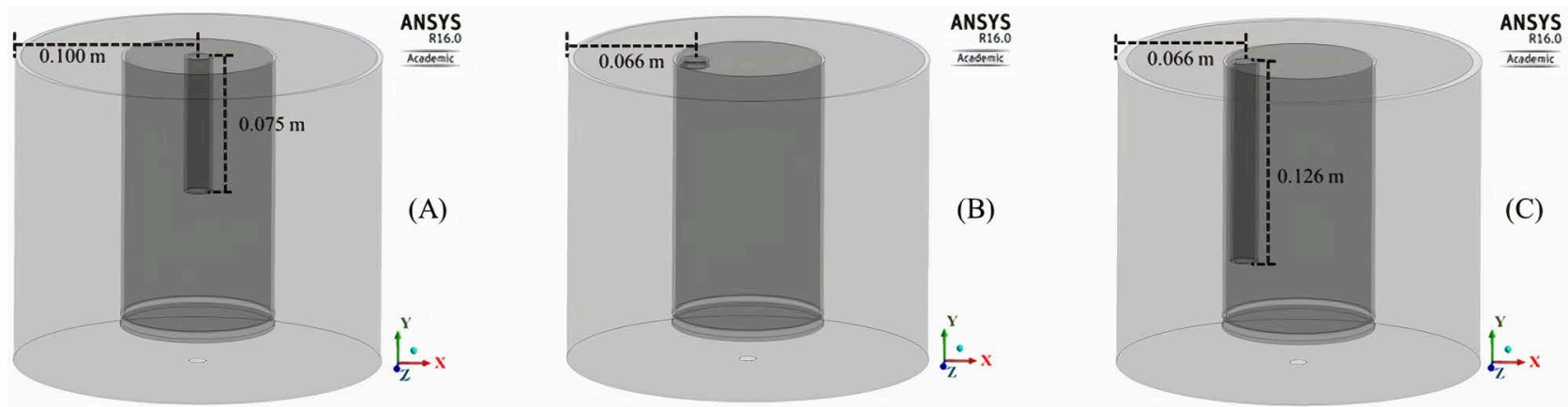

Figure 3. Geometries of the modified settlers: (A) centralized inlet; (B) without feed pipe and (C) with feed pipe increased in length. 
2) Dimensions of the settler: four configurations were studied. Two cases (cases 05 and 06) with increased settler depth, but with fixed tank diameter. And two cases (cases 07 and 08) with larger tank diameter and original depth.

3) Settler bottom: three new designs of tanks with the conical bottom of different inclination angles with the horizontal $\left(1^{\circ}, 5^{\circ}\right.$, and $\left.8^{\circ}\right)$ were studied, as shown in Figure 4.

The blocking used for generating new meshes was the same as for the original settler, making only the necessary associations of points, edges, and surfaces. The meshes obtained followed the same methodology adopted for the original tank. For each case, the mesh refinement test was performed, resulting in the appropriate mesh sizes, described in Table 1 . The mesh behavior was verified in face of quality criteria, observing that, for all meshes used, the values were adequate for the parameters.

\subsection{CFD Simulations}

The equations of mass conservation, momentum conservation, and turbulence were solved by the finite volume method, using the ANSYS-CFX package (version 16.0). The coupling between velocity and pressure is handled implicitly by a solver. The advection terms are discretized using the High-Resolution Scheme, which is second-order accurate. For all the simulations, the values of $\mathrm{y}^{+}$were less than 1 (around 0.8).

The Root Mean Square (RMS) convergence criterion adopted was $10^{-5}$. Furthermore, the solid flow in the clarified outlet was monitored; the convergence was reached when the number of particles in this tank output did not present alteration.

Concerning boundary conditions, in the inlet, were specified the suspension flow (water and solid particles) equal to $43.5 \mathrm{~g} \cdot \mathrm{s}^{-1}$. And in the sludge and clarified outlets, it was established a flow rate of $15.5 \mathrm{~g} \cdot \mathrm{s}^{-1}$ and a mean static pressure of 1 atm, respectively, also used in the experimental study. The inlet volume fraction was studied with the constant values between $1 \%$ and $20 \%$ of the solid phase; the carbonate diameter was assumed constant and equal to $25 \mu \mathrm{m}$.

To quantify the equipment separation efficiency was employed the Equation (9), also used by Al-Sammarraee et al. [12]:
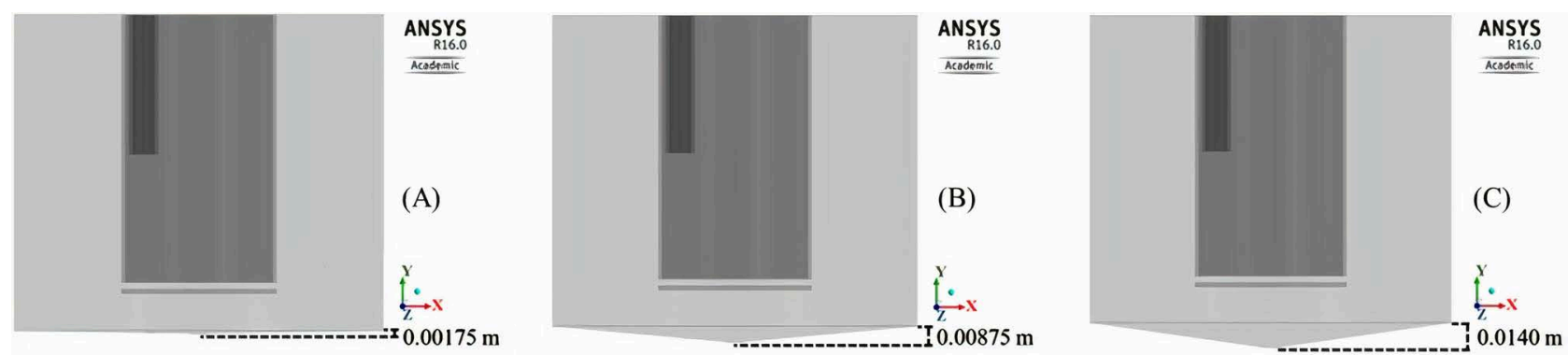

Figure 4. Dimensions of the conical base added to the settler with different angles of inclination with the horizontal (A) $1^{\circ}$; (B) $5^{\circ}$ and (C) $8^{\circ}$. 


$$
E(\%)=100 \cdot\left(1-\frac{C_{L}}{C_{o}}\right)
$$

where $E$ corresponds to the liquid/solid separation efficiency; $C_{L}$ and $C_{o}$ is the mass fraction of the solid particles in the clarified outlet and the mass fraction of solids in the settler feeding, respectively.

\section{Results and Discussion}

All simulations were performed considering the BSL RSM turbulence model, which accurately represented the velocity profiles in the settler tank, validated with experimental data from PIV (Particle Image Velocimetry) in a previous paper [22].

Luna et al. [22] compared the numeric results obtained using the BSL RSM turbulence model and the two equations models (RNG $\kappa-\varepsilon$ and SST ) to the experimental data (PIV), observing that the velocity fields calculated by the BSL-RSM turbulence model were in accordance with the average experimental data. However, the velocity results obtained through the RNG $\kappa-\varepsilon$ and SST models failed to correctly represent the velocity field. This can be justified by the fact that BSL-RSM model does not use the Boussinesq hypothesis in its formulation and presents an accurate prediction of the boundary layer flow [29].

The Euler-Euler multiphase approach allowed the accurate evaluation of the separation efficiency, and, it was possible to observe agreement between the separation efficiency values obtained numerically and experimentally [22], as observed in Figure 5.

\subsection{Influence of the Inlet Geometry}

\subsubsection{Centralized Inlet}

The turbulent kinetic energy, on an $X Y$ plane, going through the settler central axis $(z=0)$ ), is exhibited (Figure 6). Inside the feedwell, the turbulent kinetic energy was less distributed on the plane for the case of the centralized inlet. Analyzing it only in the feedwell external region (Figure 6), the settler with the centralized inlet is verified to exhibited higher turbulent kinetic energy values in the proximities of the clarified outlet (on top of the equipment) concerning to the original settler. For Shahrokhi et al. [4], the lower the value of turbulent kinetic energy, the easier flow pattern will have uniformity in the settlers, which is desirable for the particles to have more chances of being removed with a constant velocity within a smaller period time.

Figure 7 shows the volume fraction profiles of the solid phase on the $X Y$ plane, which represents the longitudinal value through the central axis of the settler. The solid volume fraction for the centralized inlet was zero in the superior region of the feedwell, which must be a disadvantage. In many situations, the feedwell is used for flocculating particles and, therefore, the occurrence of a higher mixture in this region is necessary [16]. For both cases, there were deposits of solid particles on the feedwell base. 


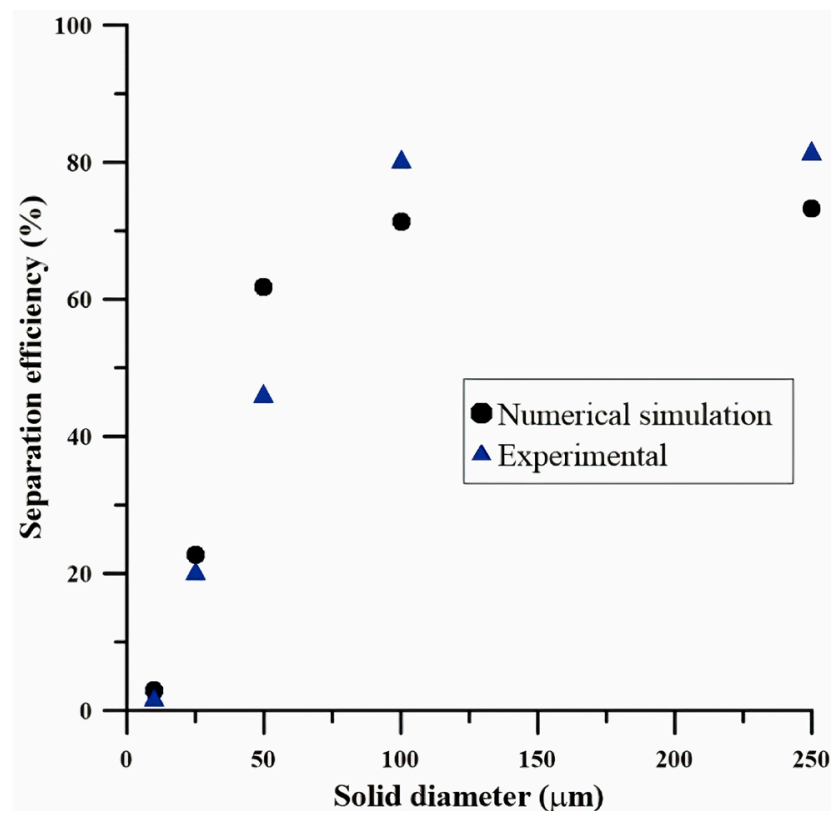

Figure 5. Separation efficiency as a function of the solid phase diameter obtained using the original settler. Source: Luna et al. [22].
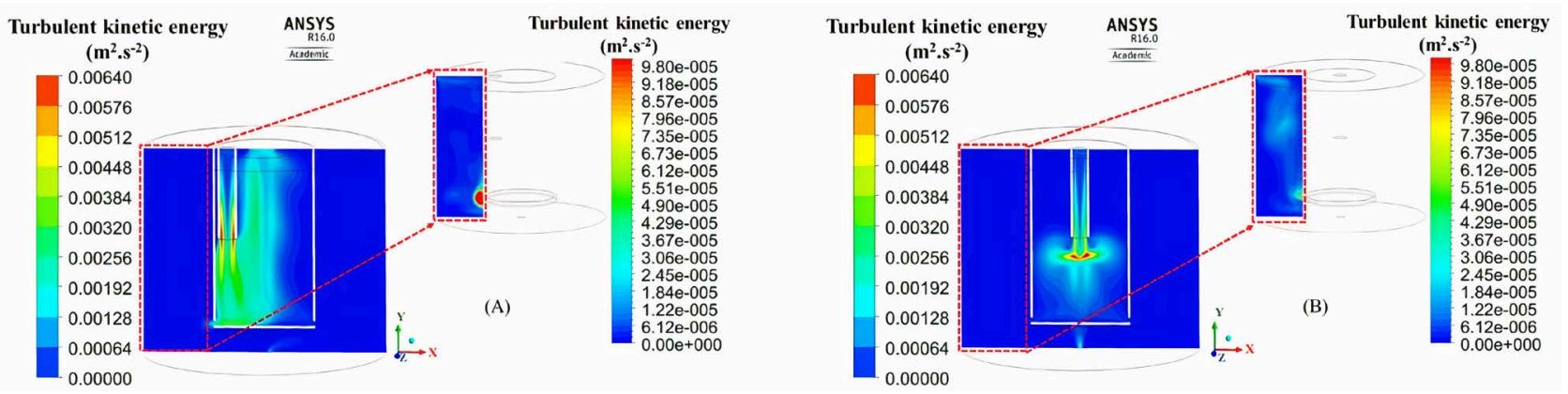

Figure 6. Turbulent kinetic energy (for the cases with volume fraction of carbonate equal to $10 \%$ in the inlet): (A) local inlet and (B) centralized inlet.

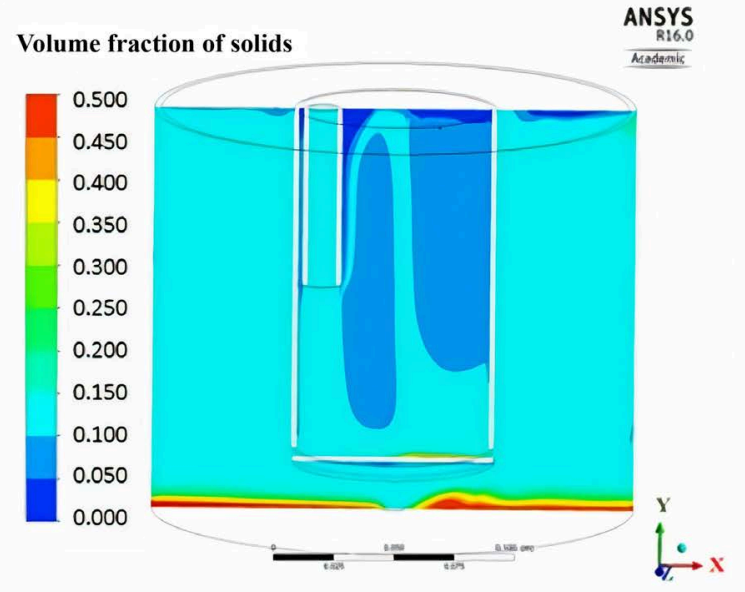

(A)

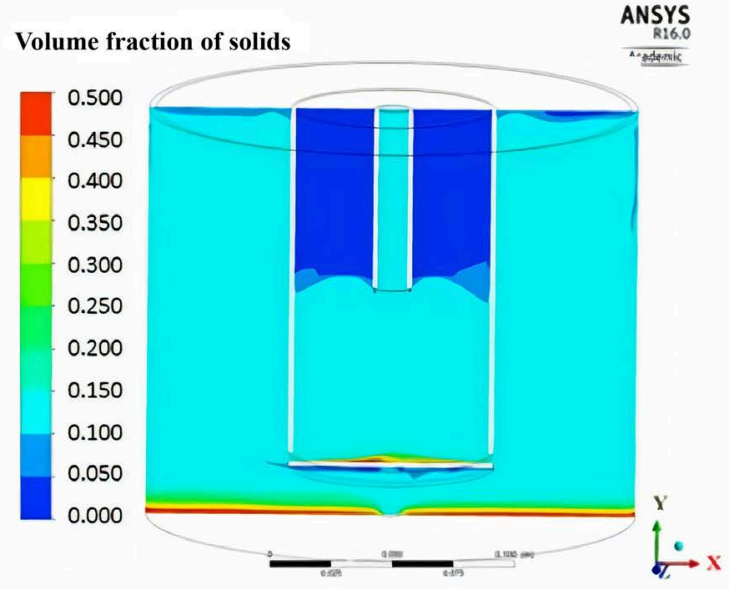

(B)

Figure 7. Volume fraction of the solid (for the cases with volume fraction of carbonate equal to $10 \%$ in the inlet): (A) local inlet and (B) centralized inlet. 


\subsubsection{Fluid Injection Tube Dimensions}

Figure 8 depicts streamlines on an $X Y$ plane going through the central axis ( $z=$ $0)$. A recirculation zone was observed inside the feedwell; however, the vortex height decreased as the internal tube increased, and the smaller recirculation size was observed in Figure $8(\mathrm{C})$. The smaller continuous phase velocities can be observed to occur in the case without feed pipe (Figure 8(B)).

Figure 9 shows the behavior of the calcium carbonate volumetric fraction in the $X Y$ plane. Inside the feedwell, we verified that the solid particles concentration

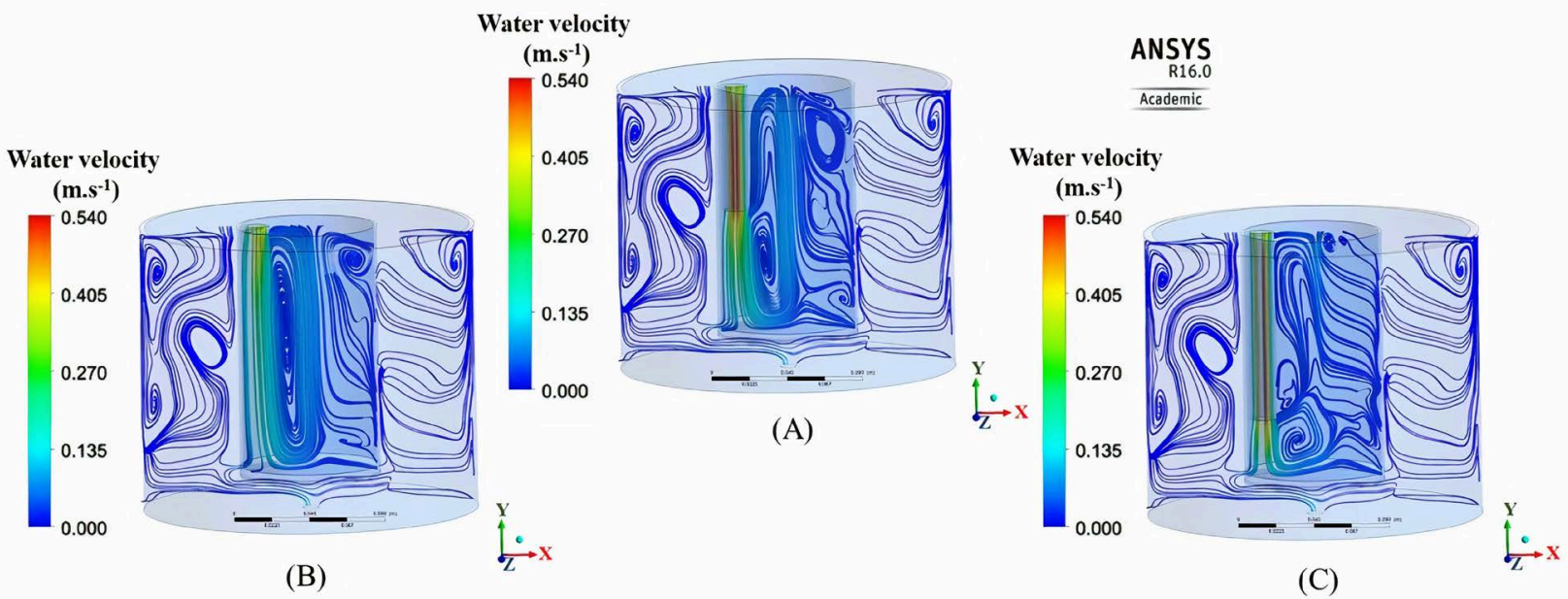

Figure 8. Streamlines (for the cases with volume fraction of carbonate equal to $10 \%$ in the inlet) of water for the cases: (A) original settler; (B) settler without feed pipe and (C) settler with increased feed pipe.

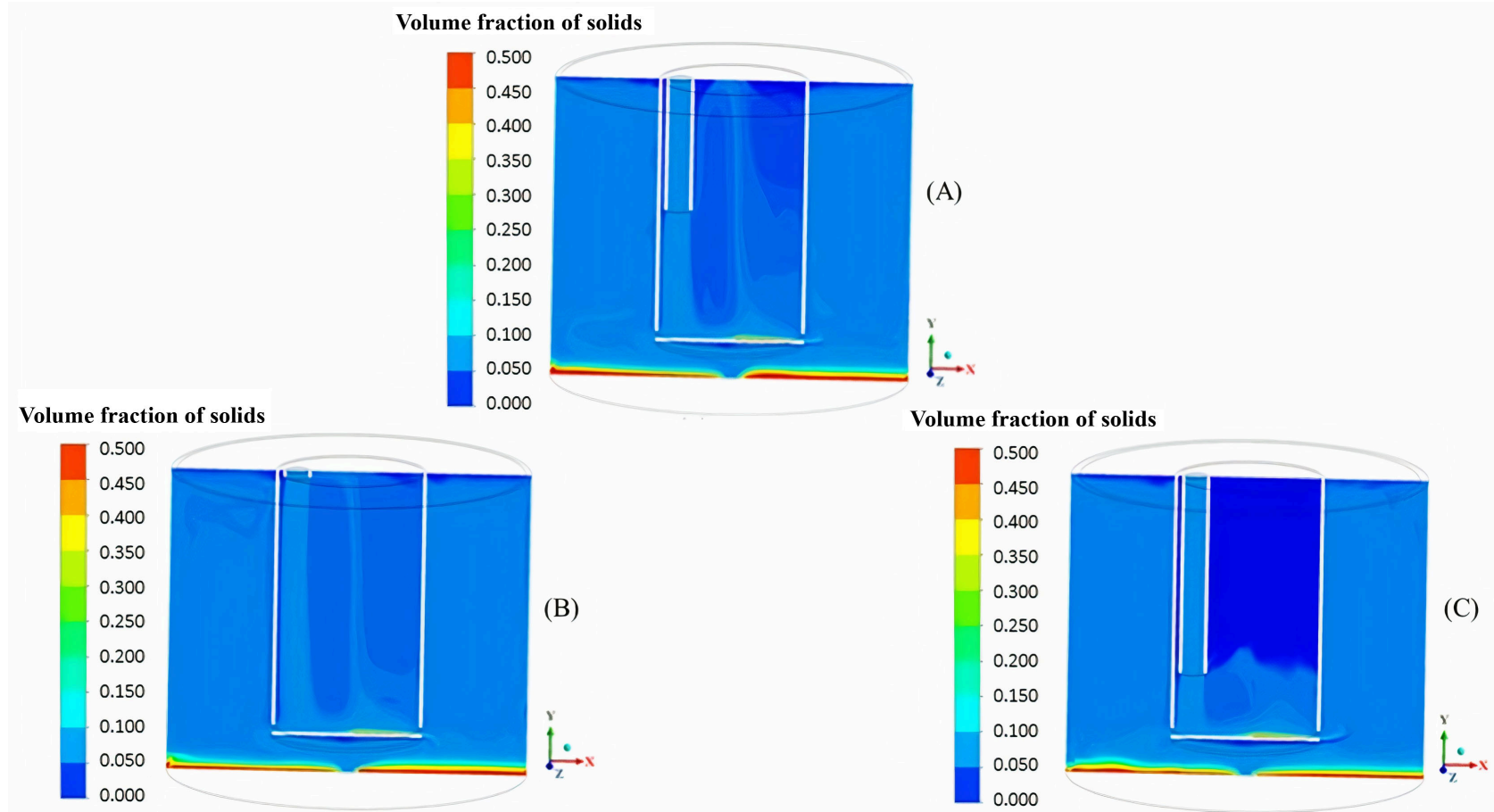

Figure 9. Volume fraction of solids (for the cases with volume fraction of carbonate equal to $10 \%$ in the inlet) on an $X Y$ plane at $Z$ $=0$ for the cases: (A) original settler; (B) settler without feed pipe and (C) settler with feed pipe increased. 
was zero (at the top) for the settler with an increased feed pipe (Figure $9(C)$ ), which is also seen in Figure 10(C) and Figure 11(C), in which volumetric fractions were presented on a horizontal plane, and $0.777 \mathrm{H}$ and $0.559 \mathrm{H}$ distant from the base, respectively, in which $\mathrm{H}$ is the depth of the settler.

In the external region of the feedwell, the settler without feed pipe is observed to present a volumetric fraction of solid values lower than the ones observed in the other settlers for the positions $0.777 \mathrm{H}$ and $0.559 \mathrm{H}$, Figure 10 and Figure 11 , respectively.

For all the cases, there was a deposit of solid particles at the bottom of the feedwell, totally undesirable for the process, these particles deposited inside the settler can be resuspended by fluid recirculations, and be directed to the clarified outlet, reducing the efficiency of separating the tank. The ideal for the process is that all particles be collected in the sludge outlet. The accumulation was elevated with the increase of the feed pipe (Figure 12). The maximum volume fraction obtained in the base was around $30 \%$ of solids.

\subsection{Influence of the Settler Tank Dimensions}

Figure 13 and Figure 14 show water streamlines in an $X Y$ plane (which regards the inlet tube) and $Y Z$ plane, respectively. Recirculations near the settler bottom were observed in the cases in which the tank depth was increased (Figure 13(D), Figure 13(E) and Figure 14(D), Figure 14(E)). For Shahrokhi et al. [5], these recirculations near the sludge outlet reduced the separation efficiency because they allowed the resuspension of particles already settled.

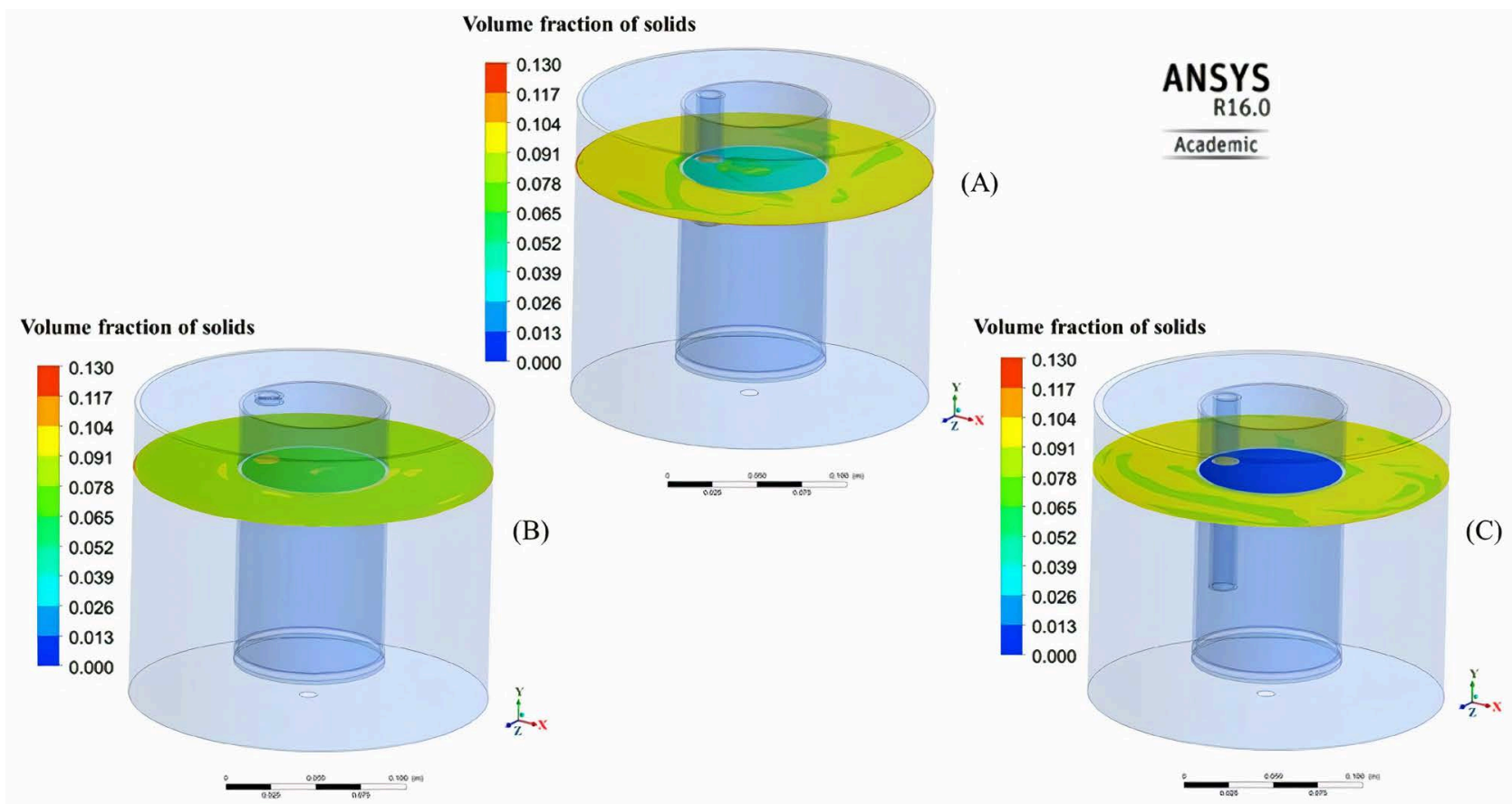

Figure 10. Volume fraction of solids (for the cases with volume fraction of carbonate equal to $10 \%$ in the inlet) on a $X Z$ in position $0.777 \mathrm{H}$ far from the bottom, for cases: (A) original settler; (B) settler without feed pipe and (C) settler with feed pipe increased. 


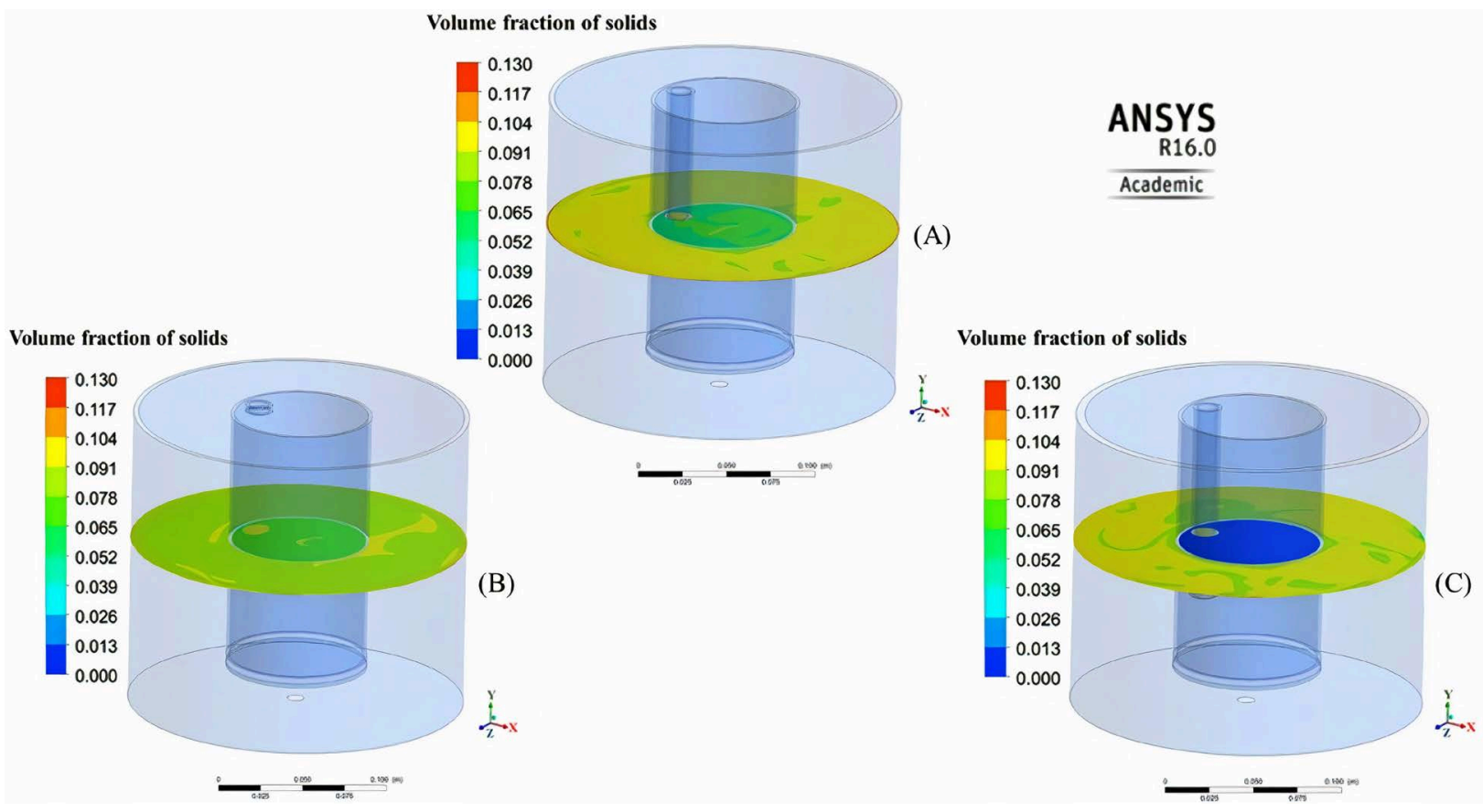

Figure 11. Volume fraction of solids (for the cases with volume fraction of carbonate equal to $10 \%$ in the inlet) on a $X Z$ in position $0.559 \mathrm{H}$ far from the bottom, for cases: (A) original settler; (B) settler without feed pipe and (C) settler with feed pipe increased.

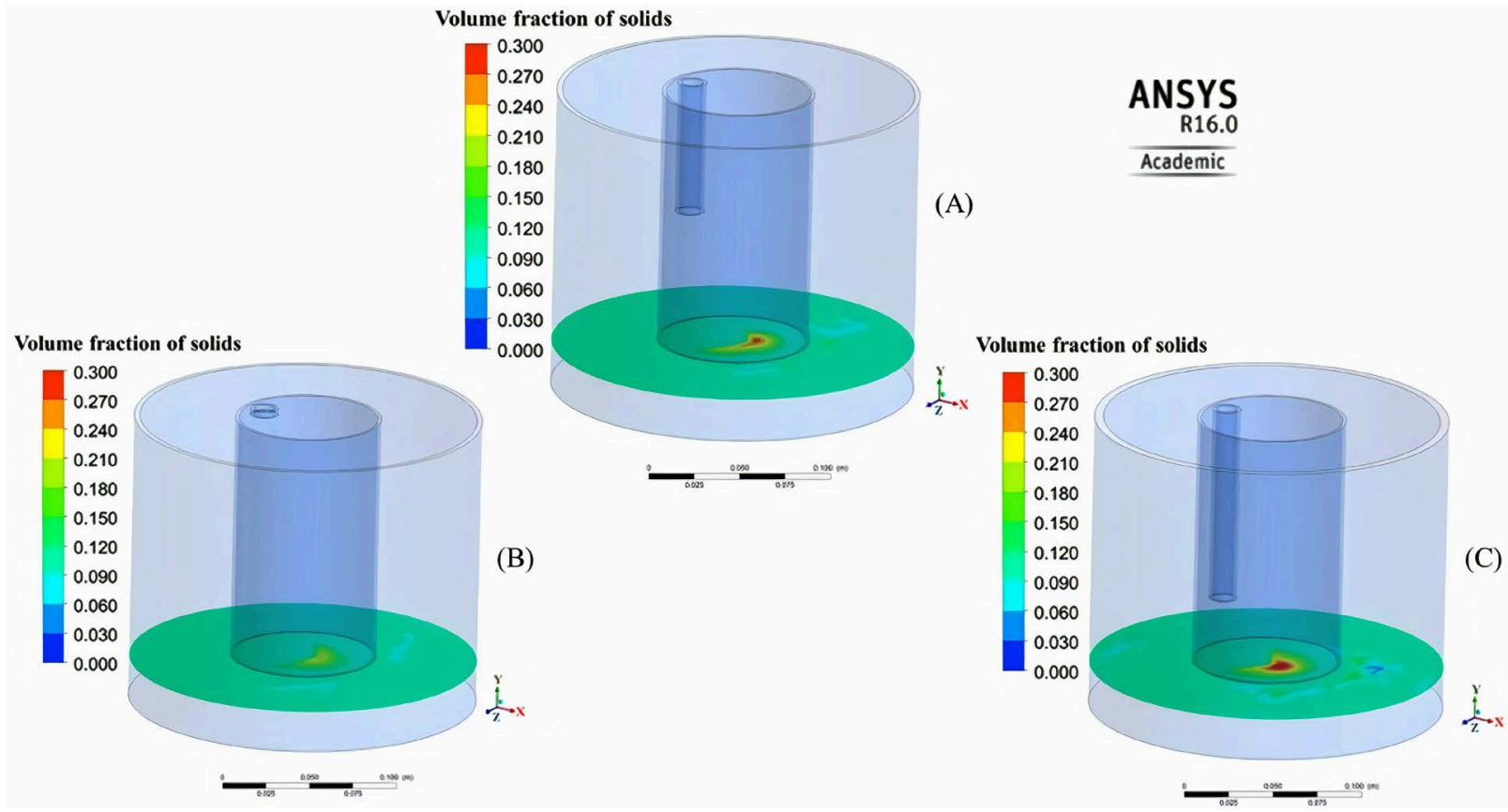

Figure 12. Volume fraction of solids (for the cases with volume fraction of carbonate equal to $10 \%$ in the inlet) on a $X Z$ in position $0.141 \mathrm{H}$ far from the bottom, for cases: (A) original settler; (B) settler without feed pipe and (C) settler with feed pipe increased.

With the increase of the sedimentation tank diameter, the recirculations of the sedimentation region were verified to be reduced; conversely, with the increase of the settler depth, the vortexes were intensified. 

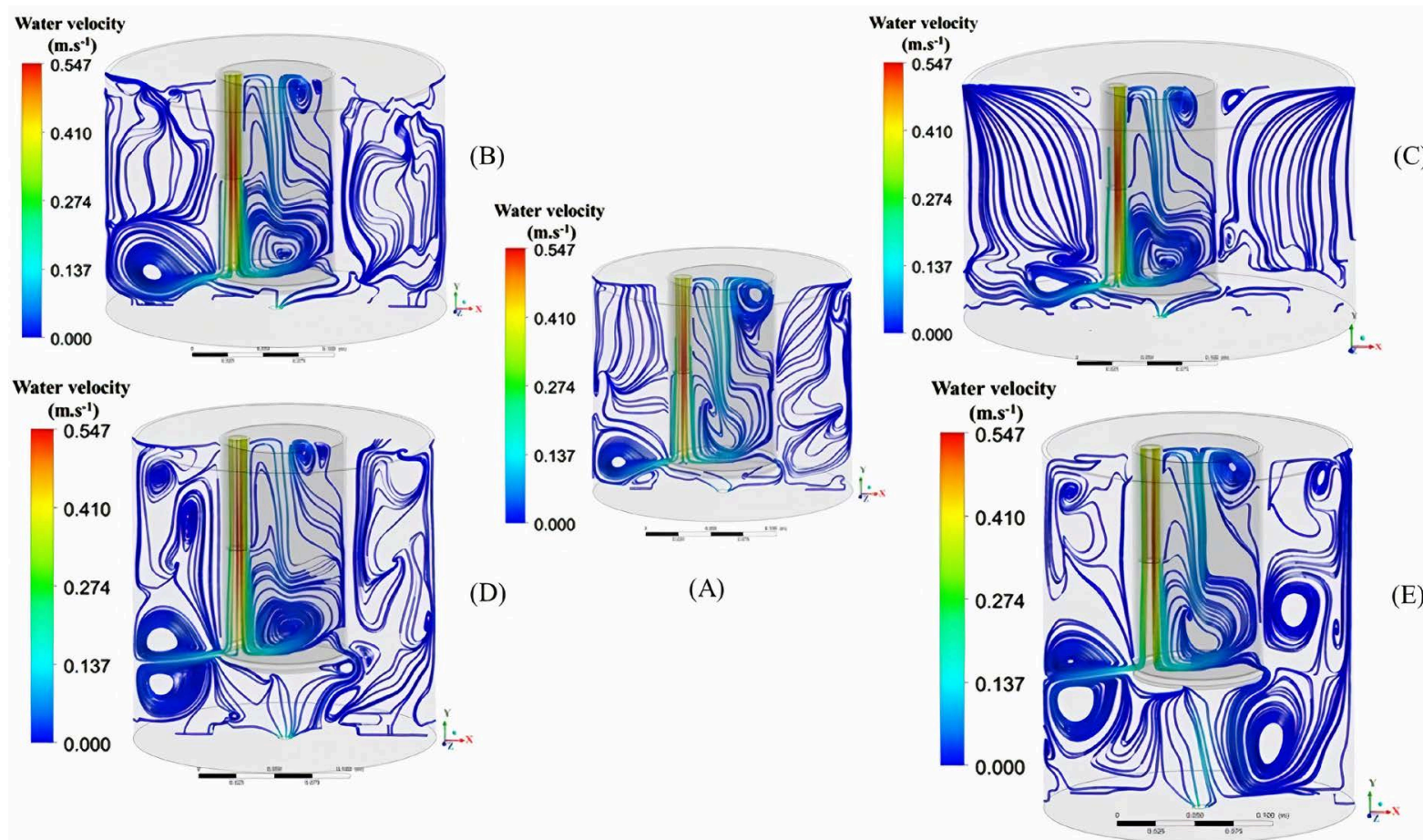

Figure 13. Streamlines of water (for the cases with volume fraction of carbonate equal to $10 \%$ in the inlet) on an $X Y$ plane, using the settlers: (A) original; (B) diameter increased by $20 \%$; (C) diameter increased by $40 \%$; (D) depth increased by $20 \%$ and (E) depth increased by $40 \%$.
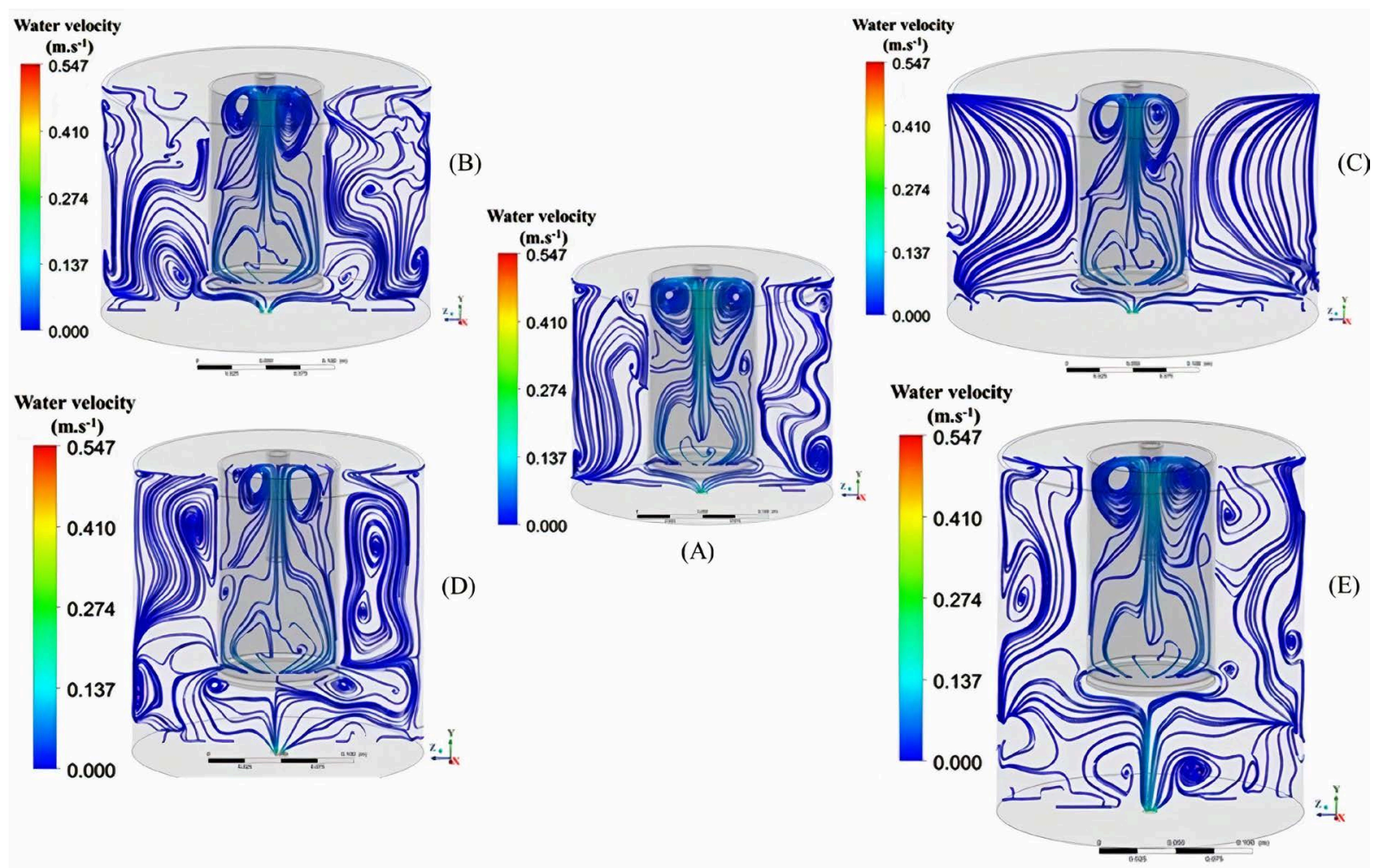

Figure 14. Streamlines of water (for the cases with the volume fraction of carbonate equal to $10 \%$ in the inlet) on another plane, the $Y Z$ plane, using the settlers: (A) original; (B) diameter increased by $20 \%$; (C) diameter increased by $40 \%$; (D) depth increased by $20 \%$ and (E) depth increased by $40 \%$. 
Inside the feedwell, all the cases presented similar behaviors: in Figure 13, a large recirculation was produced at the bottom of the feedwell (near the feeding tube), and on the $Y Z$ plane (Figure 14) was observed two recirculations in the superior region of the feedwell. Highlighting that the feedwell dimensions remained unaltered.

Figure 15 shows the planes of turbulent kinetic energy $(X Y)$ going through the settler central axis. A more significant difference was verified for the cases of the settlers with greater heights (Figure 15(D), Figure 15(E)), presenting higher values of turbulent kinetic energy near the sludge outlet. This is undesired for the sedimentation process since the turbulent kinetic energy is associated with the mixture. This prevents the formation of uniform flow, which is necessary for depositing small particles [2] [30] [31].

Table 2 shows the separation efficiency values, which were obtained, using Equation (9), for the cases with an inlet volume fraction of $1 \%$ of calcium carbonate and $99 \%$ of water. Notice that the increase of depth reduced the separation of water and carbonate; the lower efficiency obtained was around $44.0 \%$ (case 06). The diameter increase elevated the phase separation, and case 08 shows the highest efficiency (71.28\%).

\subsection{Influence of the Sedimentation Tank Design}

Figure 16 presents the turbulent kinetic energy of the continuous phase on an

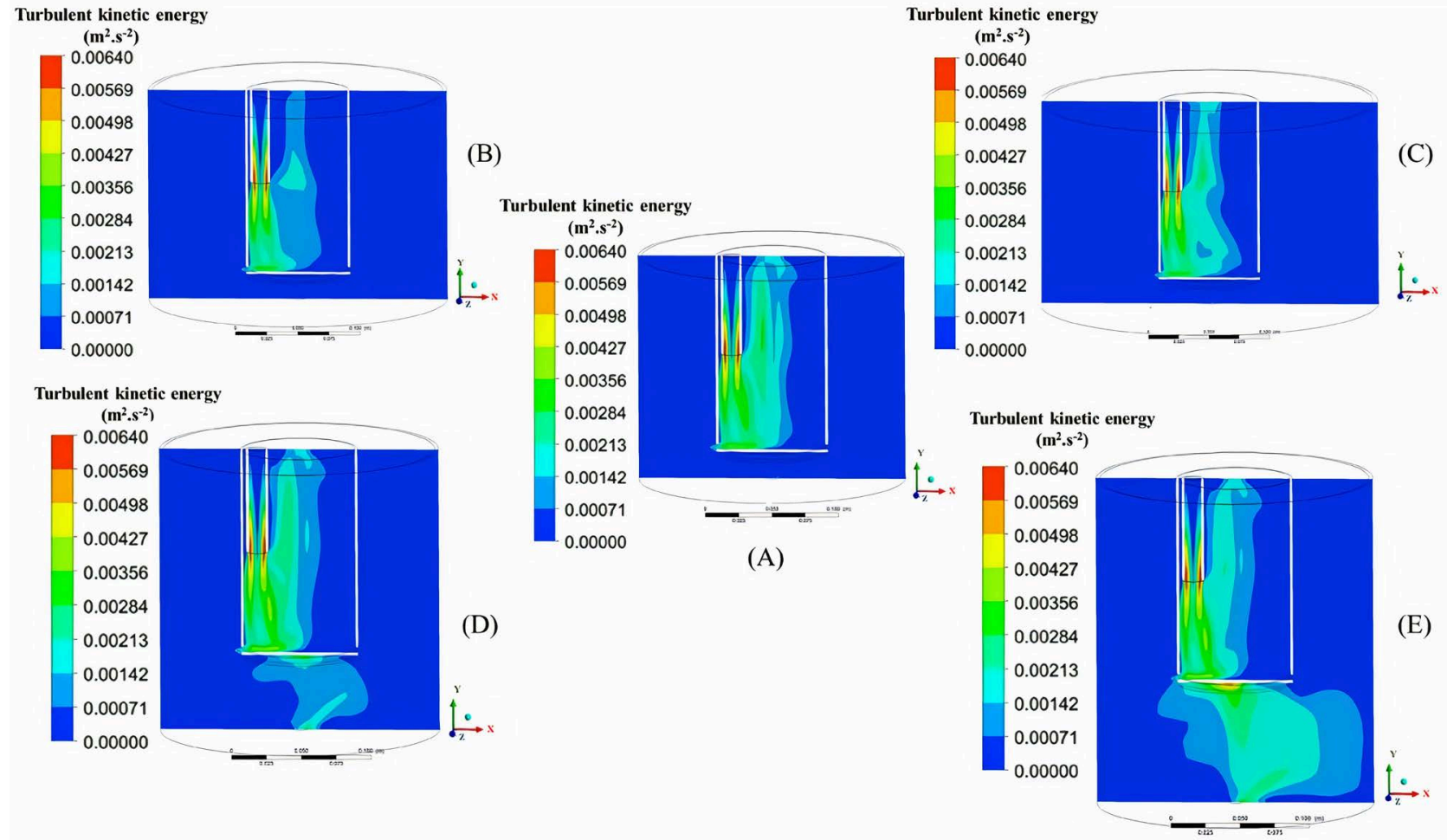

Figure 15. Turbulent kinetic energy (for the cases with volume fraction of carbonate equal to $10 \%$ in the inlet) on an $X Y$ plane, using the settlers: (A) original; (B) diameter increased by $20 \%$; (C) diameter increased by $40 \%$; (D) depth increased by $20 \%$ and (E) depth increased by $40 \%$. 

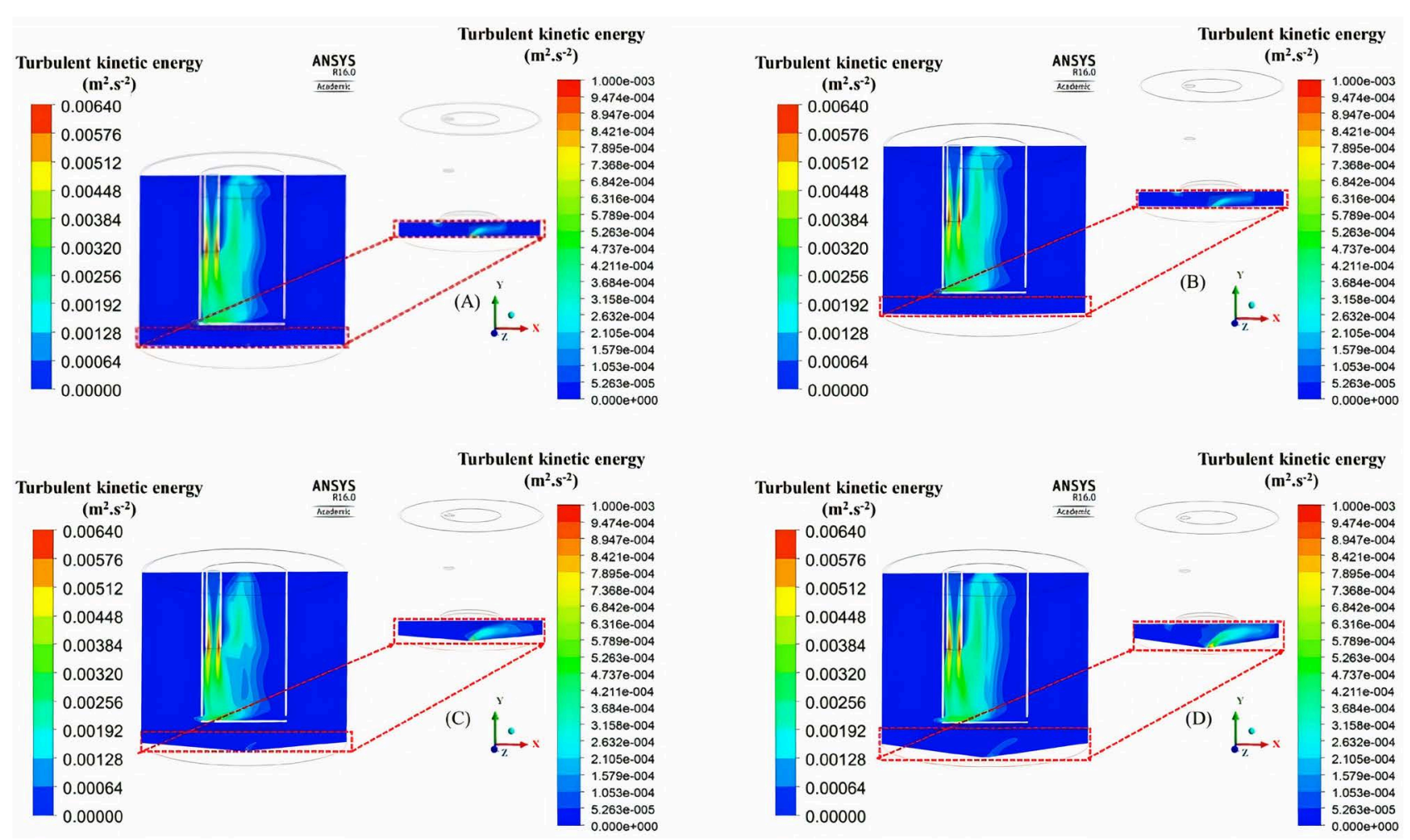

Figure 16. Turbulent kinetic energy, on an $X Y$ plane, using the settlers: (a) original; (b) with a conical base with angles of inclination $1^{\circ}$; (c) with a conical base with angles of inclination $5^{\circ}$ and (d) with a conical base with angles of inclination $8^{\circ}$.

Table 2. Separation efficiency.

\begin{tabular}{ccc}
\hline & Ratio $(\mathrm{H} / \mathrm{D})^{*}$ & Separation Efficiency (\%) \\
\hline Case 06** & 1.19 & 44.08 \\
Case 05** & 1.02 & 50.44 \\
Case 01** & 0.85 & 60.80 \\
Case 07* $^{* *}$ & 0.71 & 66.68 \\
Case 08 & 0.61 & 71.28 \\
\hline
\end{tabular}

${ }^{*} \mathrm{H}=$ Settler depth; $\mathrm{D}=$ Settler diameter. ${ }^{* *}$ For the cases with volume fraction of carbonate equal to $1 \%$ in the inlet.

$X Y$ plane going through the settler central axis $(z=0)$. It was observed that the increase of the inclination in the conical region elevated the turbulent kinetic energy value near the sludge outlet. The increase of the inclination angle lengthens the height of the studied settler. Figure 16 allows verifying that an increase in settler depth caused higher values of kinetic energy near the sludge outlet.

Table 3 presents the values of separation efficiency for each settler studied. The volumetric fraction at the inlet was set equal to $10 \%$ of calcium carbonate and $90 \%$ of water. For all the cases, the efficiency obtained was around $50 \%$. The results presented similar values. However, despite small differences, it was possible to perceive that the volume of solids in the clarified outlet increased, with the addition of the conical base. 
Table 3. Efficiency of separation obtained using the settlers with conical base.

\begin{tabular}{ccc}
\hline & Conical base & Separation Efficiency (\%) \\
\hline Case $01^{*}$ & Original settler & 49.05 \\
Case $09^{*}$ & $1^{\circ}$ & 48.64 \\
Case $10^{*}$ & $5^{\circ}$ & 47.73 \\
Case $11^{*}$ & $8^{\circ}$ & 46.82 \\
\hline
\end{tabular}

${ }^{*}$ For the cases with volume fraction of carbonate equal to $10 \%$ in the inlet.

\section{Conclusions}

The CFD simulations enable a more detailed analysis of the fluid dynamics inside the equipment, and allow design changes, that in turn may optimize the liquid-solid separation. Three aspects were evaluated: 1) feed pipe-positioning and dimension; 2) settler dimensions and 3) inclination of the tank base.

The streamlines allowed observing that the centralization and increase of the feed pipe (length) reduced the solid recirculation inside the feedwell. Consequently, the solid volumetric fraction did not spread within this region in any of the cases, which can be a disadvantage in the sedimentation process. Accumulation of solids in the feedwell base of the original settler was also verified, and all the cases presented variations in the inlet structure.

The increase of the settler depth intensified fluid recirculations inside the equipment and raised the turbulent kinetic energy near the sludge outlet, consequently reducing the equipment's separation efficiency. Conversely, the elevation of the sedimentation tank diameter reduced the turbulent kinetic energy, and enlarged the sedimentation area, resulting in tanks more efficient and profitable.

The addition of a conical region to the original settler base increased the turbulent kinetic energy near the sludge outlet and reduced the separation efficiency. The addition extended the settler's depth, which can justify the higher values of turbulent kinetic energy near the sludge outlet.

\section{Suggestions for Future Research}

Considering the results pointed out in this paper, it is suggested that the following topics be considered for further studies:

1) Quantify the presence of baffles inside the settler tank;

2) Analyze the behavior of fluid dynamics in the settler in transient solver and considering mixing with polydispersed systems, together with the flocculation and segregation of the particles.

\section{Acknowledgements}

The authors acknowledge Brazilian National Research Council (CNPq) for the financial support.

This study was financed in part by the Coordenação de Aperfeiçoamento de 
Pessoal de Nível Superior-Brazil (CAPES)_Finance Code 001.

\section{Conflicts of Interest}

The authors declare no conflicts of interest regarding the publication of this paper.

\section{References}

[1] Goula, A.M., Kostoglou, M., Karapantsios, T.D. and Zouboulis, A.L. (2007) A CFD Methodology for the Design of Sedimentation Tanks in Potable Water Treatment. Case Study: The Influence of a Feed Flow Control Baffle. Chemical Engineering Journal, 140, 110-112. https://doi.org/10.1016/j.cej.2007.09.022

[2] Al-Sammarraee, M., Chan, A., Salim, S.M. and Mahabaleswar, U.S. (2009) Large-Eddy Simulations of Particle Sedimentation in a Longitudinal Sedimentation Basin of a Water Treatment Plant. Part 1: Particle Settling Performance. Chemical Engineering Journal, 152, 307-314. https://doi.org/10.1016/j.cej.2009.04.062

[3] Rostami, F., Shahrokhi, M., Md Said, M.A. and Syafalni, R.A. (2011) Numerical Modelling on Inlet Aperture Effects on Flow Pattern in Primary Settling Tanks. Applied Mathematical Modelling, 35, 3012-3020. https://doi.org/10.1016/j.apm.2010.12.007

[4] Shahrokhi, M., Rostami, F., Md Said, A., Yazdi, S.R. and Syafalni, S. (2012) The Effect of Number of Baffles on the Improvement Efficiency of Primary Sedimentation Tanks. Applied Mathematical Modelling, 36, 3725-3735. https://doi.org/10.1016/j.apm.2011.11.001

[5] Shahrokhi, M., Rostami, F., Md Said, M.A. and Syafalni, S. (2011) Numerical Investigation of Baffle Effect on the Flow in a Rectangular Primary Sedimentation Tank. World Academy of Science, Engineering and Technology, 5, 238-243.

[6] Farrow, J.B., Fawell, P.D., Johnston, R.R.M., Nguyen, T.B., Rudman, M., Simic, K. and Swift, J.D. (2000) Recent Developments in Techniques and Methodologies for Improving Thickener Performance. Chemical Engineering Journal, 80, 149-155. https://doi.org/10.1016/S1383-5866(00)00084-8

[7] White, R.B., Sutalo, I.D. and Nguyen, T. (2003) Fluid Flow in Thickener Feedwell Models. Minerals Engineering, 16, 145-150. https://doi.org/10.1016/S0892-6875(02)00252-2

[8] Shahrokhi, M., Rostami, F., Md Said, M.A. and Syafalni, S. (2013) Numerical Modelling of Baffle Location Effects on the Flow Pattern of Primary Sedimentations Tanks. Applied Mathematical Modelling, 37, 4486-4496. https://doi.org/10.1016/j.apm.2012.09.060

[9] Sutalo, I.D., Paterson, D.A. and Rudman, M. (2003) Flow Visualisation and Computational Prediction in Thickener Rake Models. Minerals Engineering, 16, 93-102. https://doi.org/10.1016/S0892-6875(02)00256-X

[10] Ye, S., Tang, Q., Wang, Y. and Fei, W. (2016) PIV Measurement and CFD Simulation of Liquid-Liquid Flow of a Settler in Rare Earths Solvent Extraction Mixer-Settler. International Journal of Heat and Fluid Flow, 62, 568-576. https://doi.org/10.1016/j.ijheatfluidflow.2016.07.014

[11] Panda, S.K., Singh, K.K., Shenoy, K.T. and Buwa, V.V. (2017) Numerical Simulations of Liquid-Liquid Flow in a Continuous Gravity Settler Using OpenFOAM and Experimental Verification. Chemical Engineering Journal, 301, 120-133. https://doi.org/10.1016/j.cej.2016.10.102 
[12] Al-Sammarraee, M. and Chan, A. (2009) Large-Eddy Simulations of Particle Sedimentation in a Longitudinal Sedimentation Basin of a Water Treatment Plant. Part 2: The Effects of Baffles. Chemical Engineering Journal, 152, 315-321. https://doi.org/10.1016/j.cej.2009.01.052

[13] Tarpagkou, R. and Pantokratoras, A. (2014) The Influence of Lamelar Settler in Sedimentation Tanks for Potable Water Treatment-A Computational Fluid Dynamic Study. Powder Technology, 268, 139-149. https://doi.org/10.1016/j.powtec.2014.08.030

[14] Rudman, M., Simic, K., Paterson, D.A., Strode, P., Brent, A. and Sutalo, I.D. (2008) Raking in Gravity Thickeners. International Journal of Mineral Processing, 86, 114-130. https://doi.org/10.1016/j.minpro.2007.12.002

[15] Goula, A.M., Kostoglou, M., Karapantsios, T.D. and Zouboulis, A.L. (2008) The Effect of Influent Temperature Variations in a Sedimentation Tank for Potable Water Treatment-A Computational Fluid Dynamics Study. Water Research, 42, 3405-3414. https://doi.org/10.1016/j.watres.2008.05.002

[16] Zhou, T., Li, M., Li, Q., Lei, B., Chenn, Q. and Zhou, J. (2014) Numerical Simulation of Flow Regions in Red Mud Separation Thickener's Feedwell by Analysis of Residence-Time Distribution. Transactions of Nonferrous Metals Society of China, 24, 1117-1124. https://doi.org/10.1016/S1003-6326(14)63170-8

[17] Elghobashi, S. (1994) On Predicting Particle-Laden Turbulent Flows. Applied Scientific Research, 52, 309-329. https://doi.org/10.1007/BF00936835

[18] Tarpagkou, R. and Pantokratoras, A. (2013) CFD Methodology for Sedimentation Tanks: The Effect of Secondary Phase on Fluid Using DPM Coupled Calculations. Applied Mathematical Modelling, 37, 3478-3494. https://doi.org/10.1016/j.apm.2012.08.011

[19] Van Wachem, B.G.M. and Almstedt, A.E. (2003) Methods for Multiphase Computational Fluid Dynamics. Chemical Engineering Journal, 96, 81-98. https://doi.org/10.1016/j.cej.2003.08.025

[20] Gidaspow, D. (1994) Multiphase Flow and Fluidization: Continuum and Kinetic Theory Description with Application. Academic Press, INC, London, 467.

[21] Lopez de Bertodano, M., Lahey, J. and Jones, O.C. (1994) Phase Distribution in Bubbly Two-Phase Flow in Vertical Ducts. International Journal of Multiphase Flow, 20, 805-818. https://doi.org/10.1016/0301-9322(94)90095-7

[22] Luna, F.D.T., Silva, A.G., Fukumasu, N.K., Bazan, O., Gouveia, J.H.A., Moraes Jr., D., Yanagihana, J.I. and Vianna Jr., A.S. (2019) Fluid Dynamics in Continuous Settler. Chemical Engineering Journal, 362, 712-720. https://doi.org/10.1016/j.cej.2019.01.088

[23] Speziale, C.G., Sakar, S. and Gatski, T.B. (1991) Modelling the Pressure-Strain Correlation of Turbulence: an Invariant Dynamical Systems Approach. Journal of Fluid Mechanics, 227, 245-272. https://doi.org/10.1017/S0022112091000101

[24] Speziale, C.G., Abid, R. and Anderson, E.C. (1992) A Critical of Two-Equation Models for Near Wall Turbulence. The American Institute of Aeronautics and Astronautics-AIAA Journal, 30, 324-337. https://doi.org/10.2514/3.10922

[25] Launder, B.C., Reece, G.J. and Rodi, W. (1975) Progress in the Development of a Reynolds-Stress Turbulence Closure. Journal of Fluid Mechanics, 68, 537-566. https://doi.org/10.1017/S0022112075001814

[26] Perry, R.H., Green, D.W. and Southard, M.Z. (2018) Perry's Chemical Engineers' Handbook. 9th Edition, McGraw-Hill Education, New York, 2272.

[27] Metcalf, L., Eddy, H.P., Tchobanoglous, G., Burton, F.L. and Stensel, H.D. (1991) 
Wastewater Engineering: Treatment and Reuse. 3th Edition, McGraw-Hill Education, New York, 1408.

[28] Gheshlaghi, M.E., Goharrizi, A.S. and Shahrivar, A.A. (2013) Simulation of a Semi-Industrial Pilot Plant Thickener Using CFD Approach. International Journal of Mining Science and Technology, 23, 63-68.

https://doi.org/10.1016/j.ijmst.2013.01.010

[29] Menter, F.R., Kuntz, M. and Langtry, R. (2003) Ten Year of Industrial Experience with the SST Turbulence Model. In: Proceedings of the 4th International Symposium on Turbulence, Heat and Mass Transfer, Begell House, Inc., Redding, 625-632.

[30] Vakili, M.H. and Esfahany, M.N. (2009) CFD Analysis of Turbulence in a Baffled Stirred Tank, a Three-Compartment Model. Chemical Engineering Science, 64, 351-362. https://doi.org/10.1016/j.ces.2008.10.037

[31] Asgharzadeh, H., Firoozabadi, B. and Afshin, H. (2011) Experimental Investigation of Effects of Baffle Configurations on the Performance of a Secondary Sedimentation Tank. Scientia Iranica, 18, 938-949. https://doi.org/10.1016/j.scient.2011.07.005 